\title{
ALGUNS ASPECTOS DA SEDIMENTAÇÃO NA BAÍA DE TODOS OS SANTOS, BAHIA
}

\author{
ABILIO CARLOS DA SILVA PINTO BITTENCOURT, YEDA DE \\ ANDRADE FERREIRA e ENRICO DI NAPOLI*
}

\begin{abstract}
The bottom sediments of Baía de Todos os Santos (Brazil) can be grouped into three types: 1) recent olive gray mud facies occurring in the northern half of the bay in shallow and calm waters; 2) relict yellowish gray quartz sand facies occupying the two channels through which circulation with the open sea is maintained; 3) palimpsest facies consisting of: a) small isolated patches of biodetrital sediments, and b) mixed quartz sand, mud and biodetrital material found in the central part of the bay and at the mouth of the Paraguaçu River. The biogenic deposits consist mainly of corroded and perforated mollusc shells.

During the last glacial age clastic sediments were brought into the bay by the Paraguaçu River. These sediments were subsequently reworked along the shoreline during the "Flandrian" transgressive episode that elevated sea level to as much as $5 \mathrm{~m}$ above the present standpoint.

The accumulation of shell deposits started near the end of the "Flandrian". After drowning of the Paraguaçu River and completion of the shell deposits, silt-clay deposition was initiated and continues to the present day.
\end{abstract}

INTRODUÇÃo A Baía de Todos os Santos foi mencionada por Mabesoone e Coutinho (1970) como uma das menos conhecidas baías da costa brasileira, do ponto de vista das suas características sedimentologico-ambientais. Até então, poucas amostras haviam sido coletadas, todas mais ou menos próximas do porto de Salvador, pelo navio oceanográfico Calypso (Mabesoone e Coutinho, 1970). Essa situação começou a mudar a partir de 1970, com as criaç̃es, na Universidade Federal da Bahia, do Instituto Geociências e do Programa de Pesquisa e Pós-Graduação em Geofisica, que, conjuntamente, iniciaram o programa de pesquisa "Geofísica do Fundo do Mar e Sedimentos Recentes da Baía de Todos os Santos". Inicialmente os trabalhos concentraram-se nos estudos de sedimentos recentes na costa atlântica de Salvador (Estevam, 1971; Bittencourt, 1975), na costa do lado leste da baía (Vilas Boas, 1971; Machado, 1971) e, ainda, num depósito conchífero situado no interior da baía (Leão, 1971). Posteriormente, foram realizados estudos de detalhe nos sedimentos de fundo da foz do Rio Paraguaçu (Brichta, 1973) e na Baía de Aratu (Bittencourt et al., 1974).

No presente trabalho são apresentados os resultados dos estudos sedimentológicos efetuados em amostras coletadas no fundo da Baía de Todos os Santos. São considerados, também, dados relativos aos depósitos conchíferos do fundo da baía, colhidos na Companhia de Cimento Salvador (COCISA), que explora esses materiais. Visou-se, como um objetivo principal, apresentar um quadro da distribuição e caracterização das fácies sedimentares de fundo.

A baía (Fig. 1), com uma área de cerca de $800 \mathrm{~km}^{2}$, apresenta um aspecto recortado, notando-se a presença de diversas ilhas de diferentes tamanhos, particularmente concentradas na parte norte. A maior delas, Itaparica, na entrada da baía, delimita dois canais: o primeiro, Canal de Itaparica, a oeste, bastante estreito e pouco profundo, e o segundo, aqui denominado de Canal de Itaparica-Salvador, a leste, largo e profundo. Um dos maiores rios do Estado da Bahia, o Paraguaçu, desemboca na costa do lado oeste da baía em forma de estuário. Outros pequenos rios e riachos deságuam em volta de toda a baía.

*Instituto de Geociências, Universidade Federal da Bahia, Salvador, Bahia 


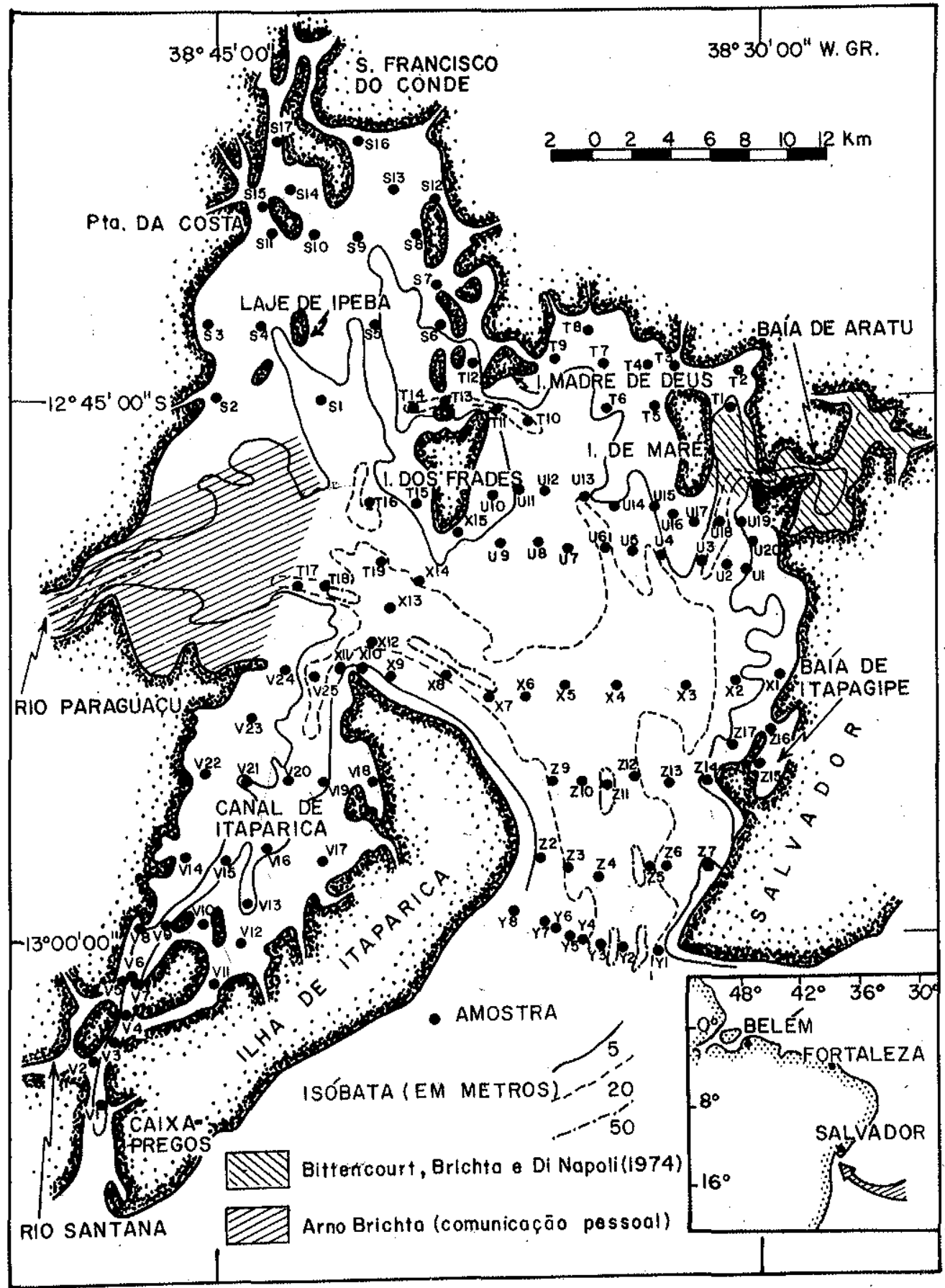

Figura I - Fisingratia e localizaçă dats amostrats 
A maior parte da baía apresenta uma topografia de fundo relativamente plana, com profundidades entre 2 e $10 \mathrm{~m}$. Profundidades maiores que $20 \mathrm{~m}$ são encontradas em alguns canais entre as ilhas, na foz do Rio Paraguaçu e no Canal de Itaparica-Salvador, onde atingem valores maiores do que $30 \mathrm{~m}$, em média, podendo, localmente, exceder os $50 \mathrm{~m}$.

Numerosos bancos (altosnfundos) pontilham por toda a baía, particularmente na parte norte, a oeste da Itha de Itaparica e ao sul de Caixa-Pregos, alguns aflorando na baixa-mar. Recifes de corais bordam, quase que continuamente, a parte leste e sudeste da Itha de Itaparica.

De uma maneira geral, a topografia das áreas adjacentes é relativamente plana, com morros isolados atingindo cotas de $50 \mathrm{~m}$, em média. $\mathrm{O}$ trecho da costa do lado leste da baía, principalmente defronte ao Canal de Itaparica-Salvador, caracteriza-se por um relevo bem movimentado. Terraços litorâneos, com cotas inferiores a $5 \mathrm{~m}$, são encontrados ao longo das costas dos lados oeste e norte da Báa de Todos os Santos e na costa sudeste da llha de Itaparica.

Praias propriamente ditas, com estirâncios e bermas, são encontradas nas costas do lado leste da baía (com exceção da Baía de Aratu) e da Ilha de Itaparica, na costa do lado oeste da baía, entre a foz do Paraguaçu e a Ponta da Costa, e em alguns trechos das ilhas. As demais áreas são ocupadas pela vegetação típica dos manguesais, e cortadas por uma série de canais de maré, estreitos e-sinuosos, denominados de gamboas, por Kutner (1962), na região de Cananéia.

O clima da Baía de Todos os Santos, segundo a classificação de Koppen (Andrea, 1962), é do tipo Af, quente e úmido, com pluviosidade média anual de $1500 \mathrm{~mm}$, e precipitações maiores de abril a agosto. No interior da baía, os ventos são geralmente nordeste no verão e sudeste no inverno. Agosto é o mês dos temporais do sul, soprando algumas vezes dois ou três dias seguidamente (Diretoria de Hidrografia e Navegação, 1970); as velocidades oscilam entre 3 e $5 \mathrm{~m} / \mathrm{s}$.

As condições hidrológicas do interior da baía são pouco conhecidas, principalmente no que se refere ao padrão de circulação. Segundo Penteado (1964), a amplitude máxima das marés é de $3,60 \mathrm{~m}$. Durante a maior parte do ano, a Corrente do Brasil flui paralelamente à costa, no sentido sudoeste, penetrando na baía, nos meses de junho e julho, com uma velocidade média, medida na superficie, de 0,6 nó (Departamento de Hidrografia e Navegação, 1974). Medidas de correntes efetuadas pela Diretoria de Hidrografia e Navegação nos portos de Madre de Deus e de Salvador (Fig. 1) indicam, em ambos os casos, velocidades médias de 1,5 nó (Diretoria de Hidrografia e Navegação 1963, 1970). A presença de correntes defronte a Caixa-Pregos, puxando geralmente para a entrada do Canal de Itaparica (Diretoria de Hidrografia e Navegação, 1970) é atestada pela existência, em Caixa-Pregos (Fig. 1), de um esporão (cuspate spit) voltado para norte.

Foi coletado um total de 119 amostras (Fig. 1) utilizando-se um amostrador de fundo tipo Van Veen, com capacidade de 6 litros, instalado em um pequeno barco a motor. O posicionamento das amostras foi feito por triangulação, com o uso da bússola Brunton, fazendo-se visadas sobre pontos de referência identificáveis na costa e em carta naútica. As amostras foram processadas eliminando-se sais solúveis por lavagem e filtração com água destilada, e a matéria orgânica, com $\mathrm{H}_{2} \mathrm{O}_{2}$ a 120 volumes. Sobre cada amostra foram realizadas análise granulométrica, incluindo peneiramento e pipetagem, análise calcimétrica e observações, nas fraç̃̃es maiores do que $62 \mu \mathrm{m}$, sob lupa binocular. Foram construídas curvas granulométricas acumulativas em papel log-probabilístico, e confeccionada uma série de mapas, que incluem os dados da Baía de Aratu (Bittencourt et al., 1974) e da foz do Rio Paraguaçu (Brichta, 1973, e comunicação pessoal). Esses mapas expressam preferencialmente a distribuição textural dos sedimentos do fundo. Uma 


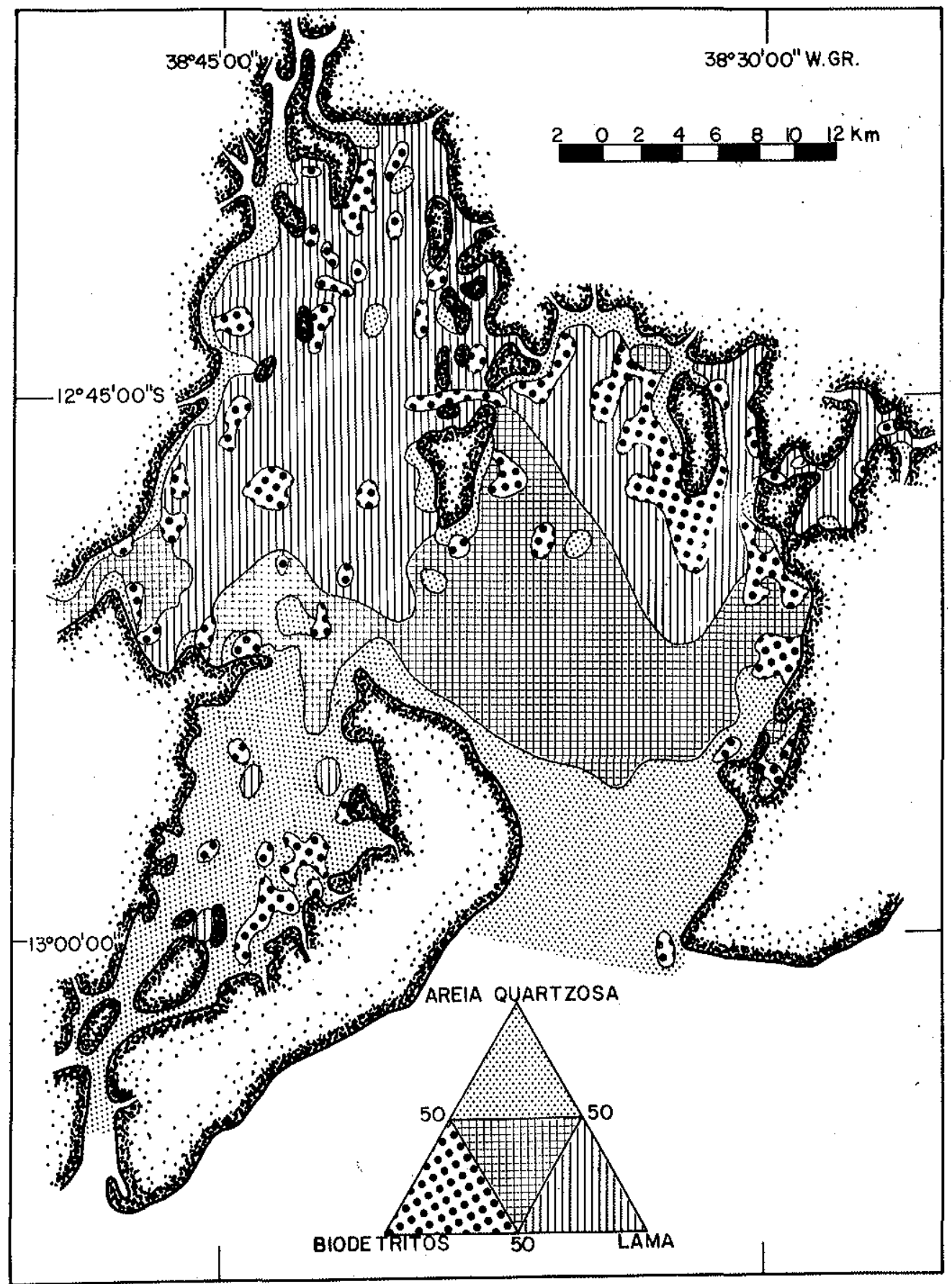

Figura 2 - Distribuição das fácies sedimentares 
tentativa de reconstituição da história geológica da Baía de Todos os Santos durante o Quaternário foi feita a partir dos dados disponíveis.

FÁGIES SEDIMENTARES - COMPOSIÇÃO Com base na composição dos sedimentos em termos dos teores de areia quartzosa (incluindo as frações silte, grânulos e seixos), lama $(<4 \mu \mathrm{m})$ e biodetritos, foi construído um mapa de fácies para a Baía de Todos os Santos (Fig. 2), semelhante ao apresentado por Mabesoone (1971) para a plataforma continental brasileira. As amostras com mais de $50 \%$ de silte, por serem muito raras, foram mapeadas como areia quartzosa. Distinguem-se, bem-marcadas, quatro fácies sedimentares: a) fácies de areia quartzosa, b) fácies de lama, c) fácies mista, e d) fácies de biodetritos.

Os estudos efetuados na fração grosseira de algumas amostras, segundo a técnica desenvolvida por" Shepard e Moore (1954), permitiram a seguinte caracterização das făcies.

FÁCIES DE AREIA QUARTZOSA As duas áreas de maior expressão de'sa fácies, os dois canais limitados pela Ilha de Itaparica, apresentam certas características composicionais que possibilitam uma distinção entre as mesmas.

Canal de Itaparica Sedimentos com coloração variando de oliva a acinzentada, tendo como principal constituinte grãos de quartzo e, em parte, biodetritos. Os grãos de quartzo, subangulares a subarredondados em sua maioria, apresentam-se envolvidos por uma película de argila. Entre os biodetritos, geralmente inferiores a $20 \%$, predominam conchas e fragmentos esqueletais de moluscos e equinodermas e, em menor parte, de briozoários e foraminíferos (raros). Fragmentos de vegetais são encontrados ao longo dos bordos (manguesais), notadamente na frente dos riachos e gamboas, quando podem atingir $25 \%$ da fração grosseira. Chamosita está presente na forma de preenchimentos de organismos, podendo, localmente, atingir os $20 \%$ da fração grosseira. Na frente do Rio Santana, a chamosita apresenta-se alterada para goetita, caráter já encontrado por Bittencourt et al. (1974) na Baía de Aratu. Minerais pesados são raros.

Canal de Itaparica-Salvador Sedimentos com coloração cinza-amarelada, compostos dominantemente de grãos de quartzo e biodetritos (20-50\%). Os grãos de quartzo apresentam-se subarredondados a arredondados, limpos e brilhantes. Os biodetritos, em sua maioria, são representados por restos de moluscos, Halimeda, briozoários e alga coralinácea, e em parte por equinodermas e foraminiferos (ate 10\%). Fragmentos de rocha (folhelho, siltito e arenito) são encontrados em algumas amostras, com tamanhos de até $8 \mathrm{~cm}$ e, em alguns casos, recobertos por colônias de organismos calcários.

FÁCIES DE LAMA Material de coloração oliva-acinzentada e constituído, predominantemente, de argila $(>50 \%)$ e silte, com pouca areia. Entre os componentes biogênicos, predominam moluscos e equinodermas. A Halimeda é rara, embora localmente (amostras T10 e U14) possa atingir até $20 \%$ da fração grosseira. Os foraminíferos estão presentes em algumas amostras, com percentagens entre 3 e 10\%. Fragmentos vegetais aparecem nas amostras da costa do lado norte da baía (manguesais e desembocaduras de riachos e gamboas) e na região próxima à foz do Paraguaçu. No último caso, as percentagens podem atingir os $20 \%$ da fração grosseira. A chamosita, correndo na forma de pelotas fecais mineralizadas, é rara, podendo, entretanto, na foz do. Paraguaçu, atingir até $70 \%$ da fração grosseira. 
FÁCIES DE BIODETRITOS Essa fácies apresenta uma coloração acinzentada, sendo constituída de mais de $50 \%$ de componentes biogênicos. Compõe-se principalmente de restos de moluscos, equinodermas e Halimeda e, em menores percentagens, alga coralinácea e foraminíferos (raros). Leão (1971), num estudo detalhado do depósito conchífero da Lage da Ipeba (Fig. 1), distingue duas subfácies: a subfácies de Halimeda e a de ostra e Plicatula. Grãos de quartzo, quando presentes, são finos e subangulares. A argila, subordinada, está sempre presente em percentagens inferiores a 30\%. A chamosita é rara.

FÁCIES MISTA Com coloração oliva-acinzentada, é caracterizada pela mistura, em diferentes proporções, de três componentes: areia quartzosa, lama e biodetritos, sem exceder, nenhum deles, os $50 \%$ da amostra. Essa fácies apresenta uma certa diferenciação entre a parte central da baía e da foz do Paraguaçu.

Foz do Paraguą̧u O geólogo Arno Brichta (comunicação pessoal) apresenta as seguintes características para essa área. Materiais constituídos por uma mistura, em maiores percentagens de areia quartzosa (incluindo a fração silte) e lama, com poucos componentes biogênicos. Os grãos de quartzo são finos a médios, subangulares a subarredondados, alguns apresentando um filme envoltório de óxido de ferro. Entre os componentes biogênicos, sobressaem-se os moluscos. Fragmentos de vegetais aparecem em proporções que variam de 3 a $20 \%$ na fração grosseira. Raras plaquetas de mica são presentes.

Parte central da baía Maiores percentagens de componentes biogênicos do que na foz do Paraguaçu, representados predominantemente por moluscos, Halimeda e equinodermas, com alguns foraminíferos. Em sua maioria, esses materiais apresentam-se desgastados, corroídos e perfurados. Fragmentos dë folhelhos, grosseiros, são encontrados na amostra X7. A chamosita aparece em percentagens de 3 a $15 \%$ da fração grosseira.

CONCHAS E FRAGMENTOS ESQUELETAIS Os teores de conchas e de fragmentos esqueletais no sedimento, expressos pela percentagem em peso de $\mathrm{CaCO}_{3}$, estão representados na Fig. 3. Comparando-se as Figs. 2 e 3, pode-se fazer a seguinte caracterização das fácies (expressa na Tab. l), quanto aos teores de carbonatos. A fácies de lama apresenta teores inferiores a $20 \%$, à exceção de uma pequena área ao sul da ilha de Maré, com valores entre 20 e $50 \%$. Na fácies mista, distinguem-se duas áreas com diferentes percentagens de carbonatos: a foz do Paraguaçu, com valores na sua maioria inferiores a $20 \%$, e a parte central da baía, entre 20 e $50 \%$. A fácies de areia quartzosa é caracterizada no canal de Itaparica-Salvador por teores entre 20 e $50 \%$, à exceção de úma estreita faixa, logo na entrada do canal, com valores inferiores a 20\%. As demais áreas dessa fácies, de uma maneira geral, apresentam valores menores, inferiores a $20 \%$.' Por fim, a fácies de biodetritos, por definição, tem mais de $50 \%$ de carbonatos.

Os componentes biogênicos do fundo da Baía de Todos os Santos são constituídos, em grande parte, notadamente ná fácies de biodetritos, por conchas e fragmentos esqueletais desgastados, corroídos, furados e com encrustações de tubos de poliquetas e serpulídeos. Na fácies de lama, predominam conchas novas e recentes. Esse material pode ser considerado, em um primeiro enfoque, como "relíquia", no sentido definido por Emery (1968) de um material remanescente de condições ambientais do passado, atuantes no Quaternário. Uma discussão sobre o assunto, na Baía de Todos os Santos, será feita mais adiante.

TEOR DE MATÉRIA ORGÂNICA Os teores de matéria orgânica nos sedimentos de fundo da Baía de Todos os Santos, expressos pela perda em peso após ataque com $\mathrm{H}_{2} \mathrm{O}_{2}$ 


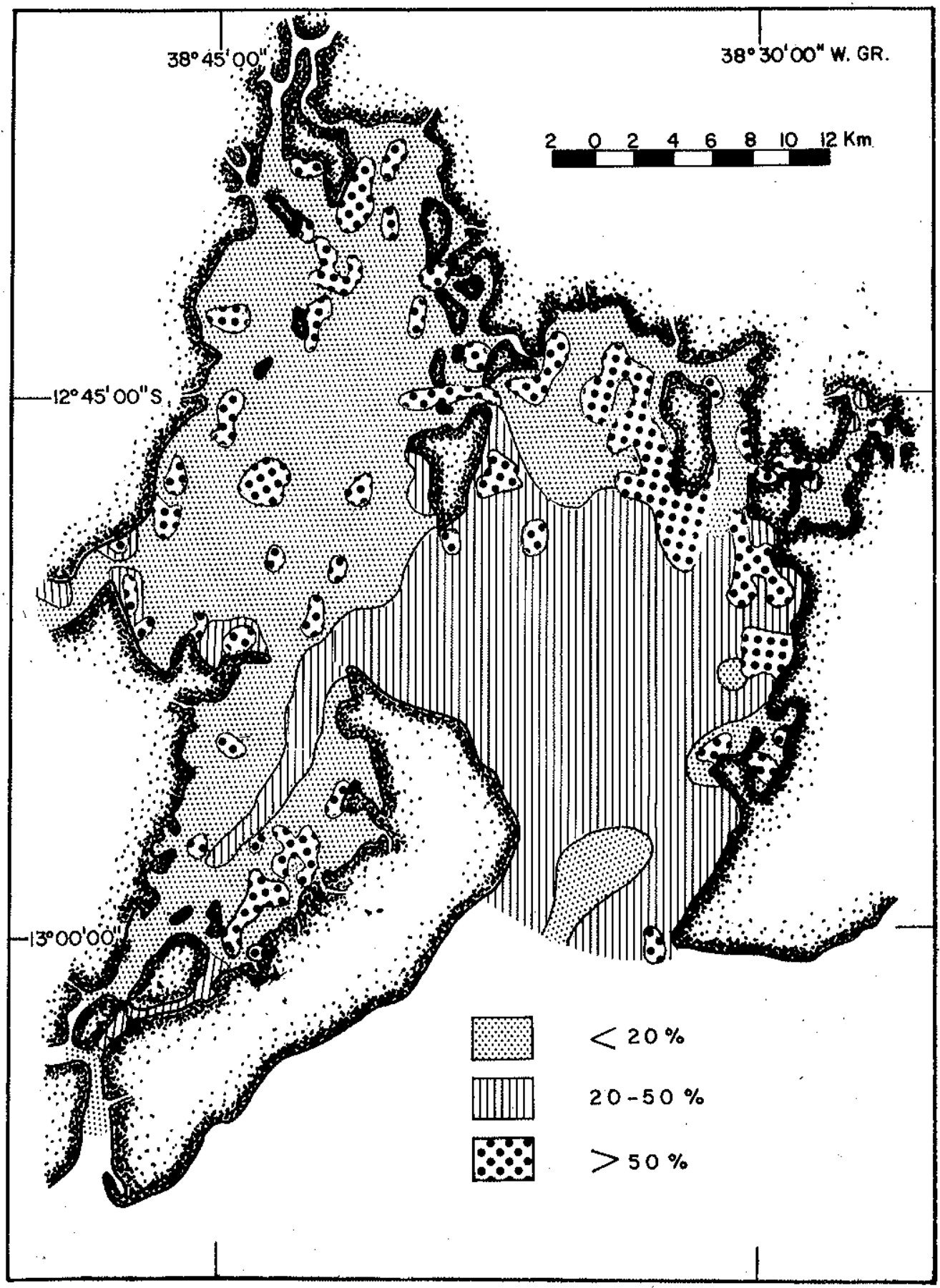

Figura 3 - Distribuição dos teores de carbonatos, em peso 
Tabela I - Características gerais das fácies sedimentares de fundo

\begin{tabular}{|c|c|c|c|c|c|c|}
\hline TIPO DE FÁClES & $\begin{aligned} \mathrm{Ca} \mathrm{CO}_{3} \\
(\%)\end{aligned}$ & $\begin{array}{c}\text { MAT. ORG. } \\
(\%)\end{array}$ & $\begin{array}{l}\text { TIPO TEXTY } \\
\text { RAL }\end{array}$ & $\begin{array}{r}\text { MEDIANA } \\
(\mu \mathrm{m})\end{array}$ & $\begin{array}{l}\text { ARGILA } \\
(\%)\end{array}$ & $\begin{array}{l}\text { "c" } \\
(\mu \mathrm{m})\end{array}$ \\
\hline LAMA & $<20$ & $3-6$ & $\begin{array}{l}\text { ARGILA }-S I_{L} \\
\text { TOSA }\end{array}$ & $<4$ & $>50$ & $62-250$ \\
\hline BIODETRITOS & 150 & $1-3$ & AREIA & $>250$ & $<30$ & $>1000$ \\
\hline $\begin{array}{l}\text { MISTA (FOZ DO PA- } \\
\text { RAQUACUU) }\end{array}$ & $<20$ & $1-3$ & $\begin{array}{l}\text { ARGILA-SIL } \\
\text { TOSA }\end{array}$ & $4-62$ & $30-50$ & $250-1000$ \\
\hline $\begin{array}{l}\text { MISTA (PARTE CEN- } \\
\text { TRAL DA BAÍA) }\end{array}$ & $20-50$ & $1-3$ & $\begin{array}{l}\text { AREIA-SILTE } \\
\text {-ARGILA }\end{array}$ & $4-62$ & $10-30$ & $250-1000$ \\
\hline $\begin{array}{l}\text { AREIA QUARTZOSA } \\
\text { (CANAL DE ITAPARICA) }\end{array}$ & $<20$ & $1-3$ & AREIA & $62-250$ & $<10$ & $>1000$ \\
\hline $\begin{array}{l}\text { AREIA QUARTZOSA } \\
\text { (CANAL ITAPARICA - } \\
\text { SALVADOR) }\end{array}$ & $20-50$ & $<1$ & AREIA & $>250$ & $<10$ & $>1000$ \\
\hline $\begin{array}{l}\text { AREIA QUARTZOSA } \\
\text { (ÁREAS MAROINAIS) }\end{array}$ & $<20$ & $1-3$ & AREIA & $62-230$ & $<30$ & $>250$ \\
\hline
\end{tabular}

a 120 volumes, estão representados na Fig. 4. Fazendo-se uma comparação geral entre as Figs. 2 e 4, observa-se que as fácies de fundo apresentam diferentes valores quanto aos teores de matéria orgânica (Tab. I). A fácies de areia quartzosa, no canal de Itaparica-Salvador, apresenta percentagens inferiores a $1 \%$. No canal de Itaparica, essa fácies tem teores mais altos, entre 1 e $3 \%$, com exceção da entrada sul do mesmo canal, em Caixa-Pregos, com valores inferiores a $1 \%$. Nas demais áreas dessa fácies, os teores estão compreendidos entre 1 e $3 \%$ : As fácies mista e de biodetritos, de uma maneira geral, têm de 1 a $3 \%$ de matéria orgânica, enquanto que a fácies de lama varia entre 3 e $6 \%$.

Os maiores teores de matéria orgânica, superiores a $6 \%$ (máximo de $11,5 \%$, amostra U3), não apresentam uma distribuição particular, restringindo-se a pequenas ocorrências, isoladas, concentradas na fácies de lama.

ASPECTOS TEXTURAIS Com o objetivo de expressar os principais aspectos texturais dos sedimentos de fundo da Baía de Todos os Santos, foi construída uma série de mapas, já reconhecidos como representativos por Bittencourt et al. (1974) da Baía de Aratu, e que guardam uma estreita correlação com o mapa de distribuição das fácies sedimentares. Desse modo, foram construídos: a) mapa de distribuição dos tipos texturais (Fig. 5), utilizando-se o triângulo de Shepard (1954), em cuja fração de areia foram inclusas as frações maiores do que $2 \mathrm{~mm}$, representadas por fragmentos de rochas, conchas inteiras e fragmentos esqueletais; b) mapa de distribuição dos teores de argila $(<4 \mu \mathrm{m})$ (Fig. 6); c) mapa de distribuição do "C" (Passega et al., 1967) (Fig. 7) e d) mapa de distribuição da mediana (Fig. 8).

A análise comparativa das Figs. 5, 6 e 7 com o mapa de fácies (Fig. 2) revela uma correspondência entre os padrões gerais desses quatro mapas, permitindo uma caracterização textural das diferentes fácies sedimentares (Tab. I). A fácies de areia quartzosa nos canais de Itaparica e de Itaparica-Salvador corresponde ao tipo textural areia, com baixos teores de argila, inferiores a $10 \%$ (em média, inferiores a $2 \%$ ) a altos valores do " $\mathrm{C}$ ", superiores a $1000 \mu \mathrm{m}$. Os demais locais de ocorrência dessa fácies, na quase totalidade, são do tipo textural areia, com teores de argila inferiores a $30 \%$ e valores do " $\mathrm{C}$ ", 


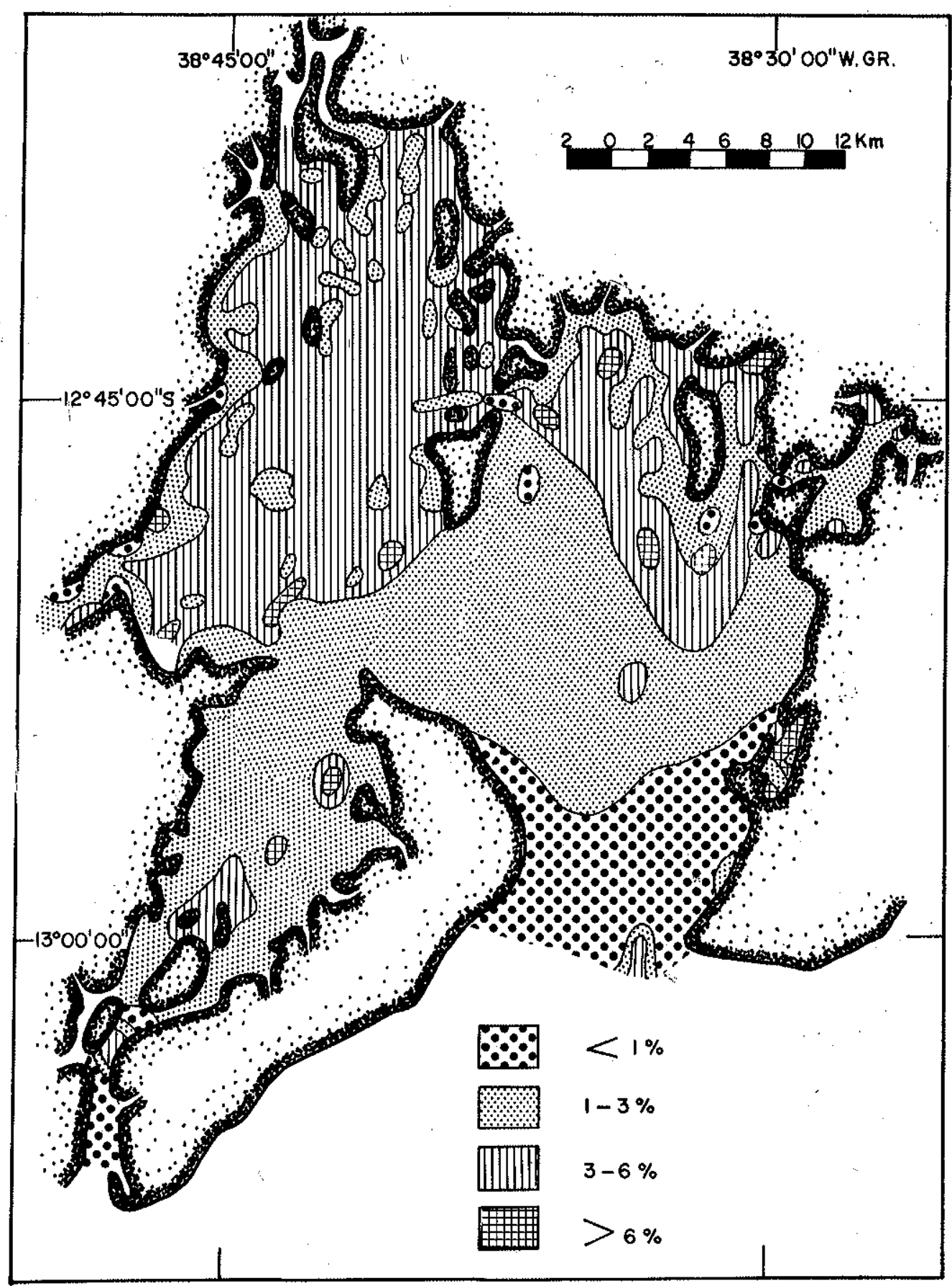

Figura 4-Distribuição dos teores de matéria orgânica, em peso 


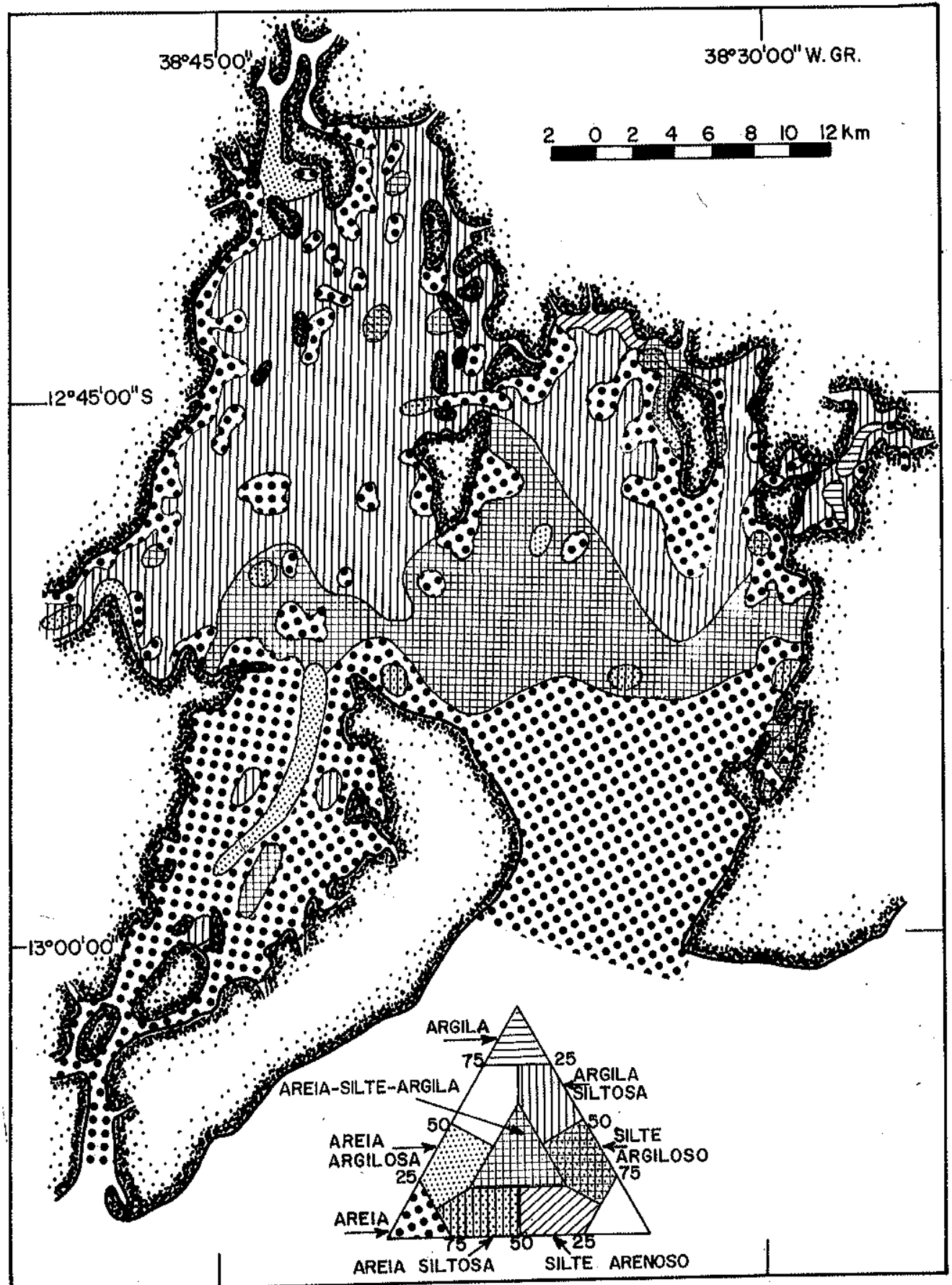

Figura 5 - O triângulo de Shepard (1954) e a distribuição dos diferentes tipos texturais 


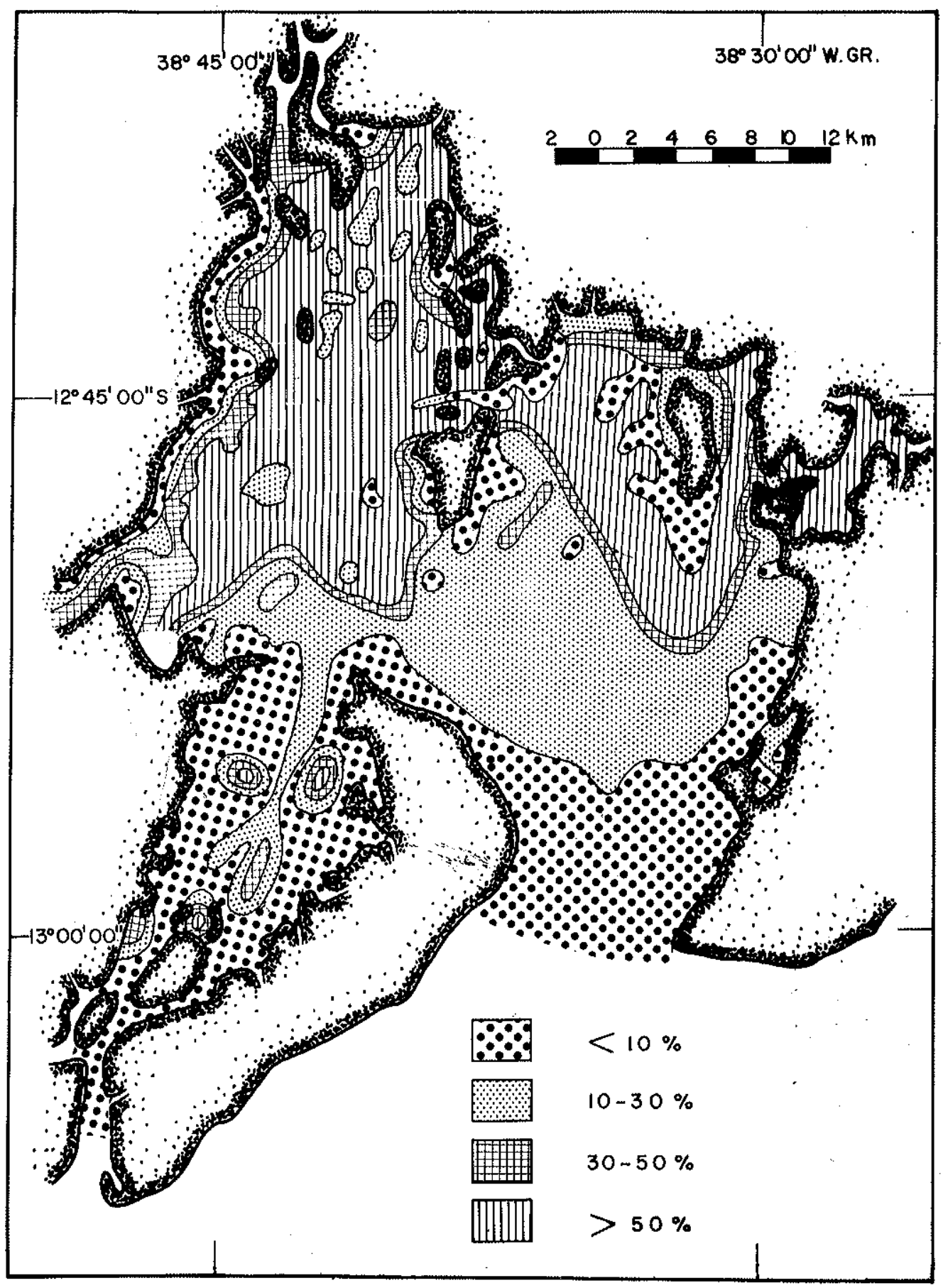

Figura 6 - Distribuição dos teores de argila 


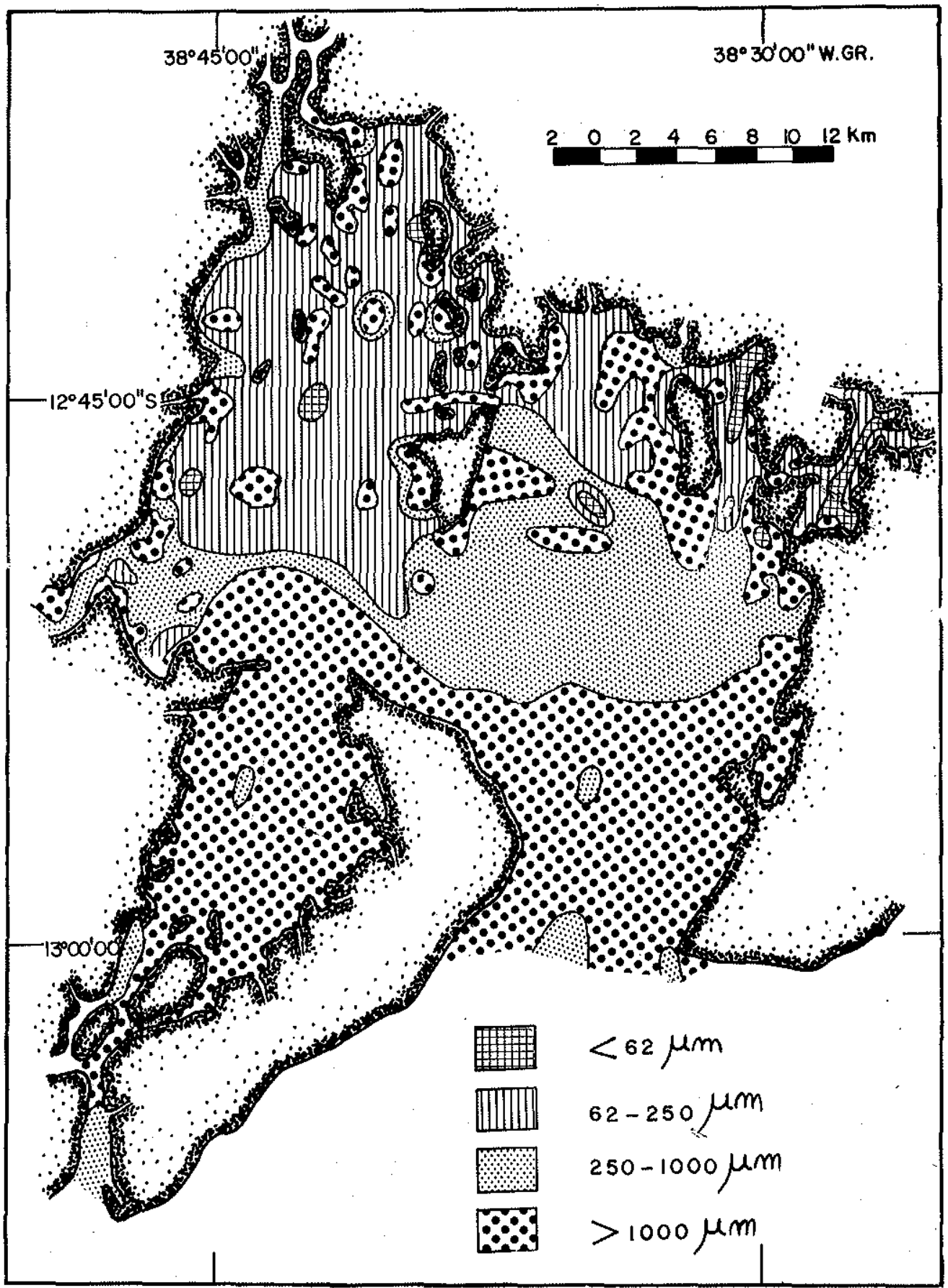

Figura 7 - Distribuição do " $\mathrm{C}$ ", correspondendo aos diametros mais grosseiros presentes nos sedimentos 


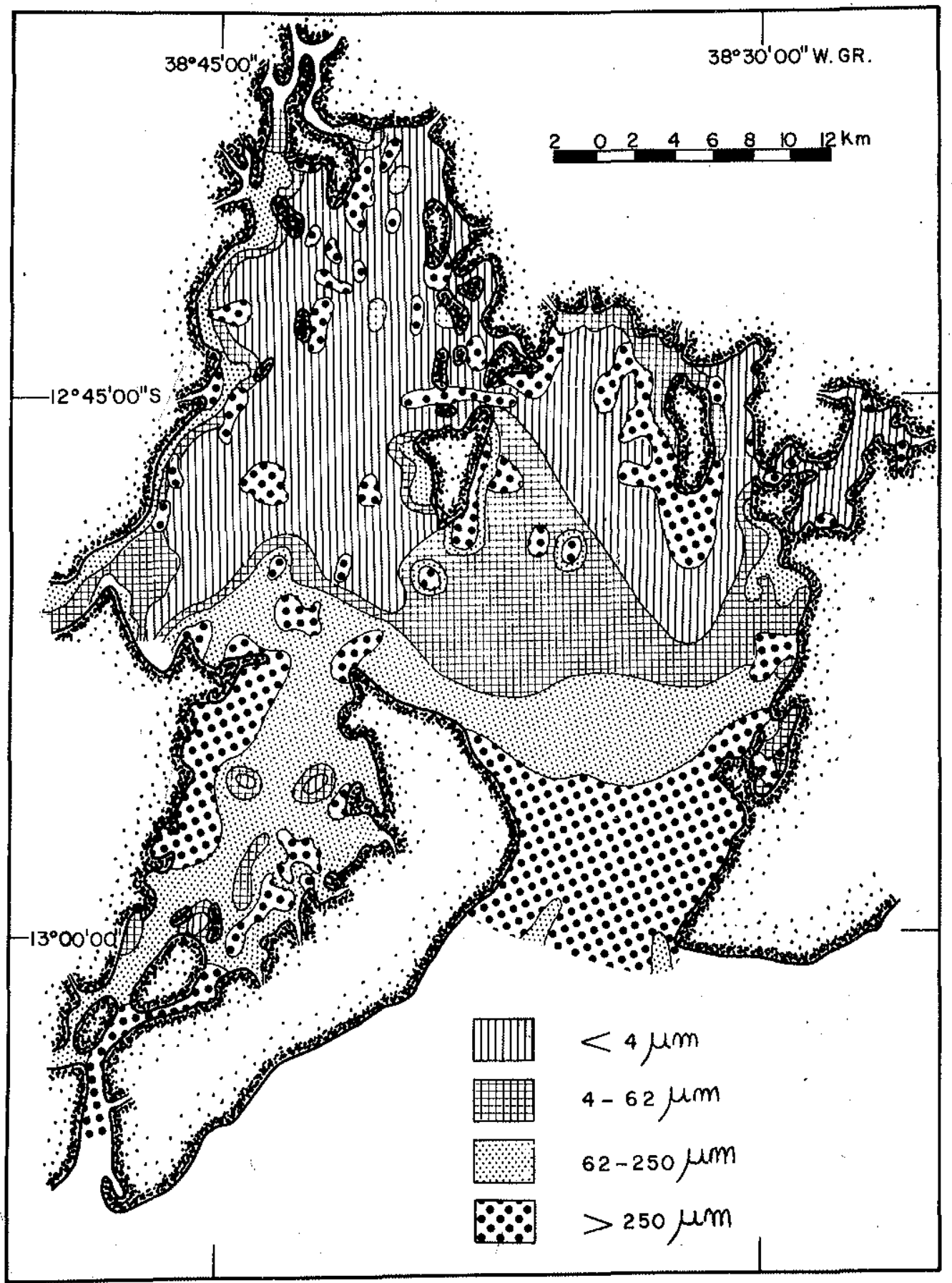

Figura 8 - Distribuição dos valores da mediana 
de uma maneira geral, superiores a $250 \mu \mathrm{m}$. A fácies de lama caracteriza-se pelo tipo textural argila siltosa, com altos teores de argila, superiores a $50 \%$ e valores do "G", entre 62 e $250 \mu \mathrm{m}$. A fácies mista apresenta duas áreas com características texturais distintas: a) parte central da baía, tipo textural areia-silte-argila, com teores de argila entre $10 \mathrm{e}$ $30 \%$ e valores do " $\mathrm{C}$ " entre 250 e $1000 \mu \mathrm{m}$ e b) foz do Paraguaçu, predominando tipo textural argilo-siltosa, teores de argila entre 30 e $50 \%$, e valores do " $\mathrm{C}$ " entre 250 e $1000 \mu \mathrm{m}$. Por fim, a fácies de biodetritos, tem tipo textural areia, com teores de argila inferiores a $30 \%$ e valores do " $\mathrm{G}$ " superiores a $1000 \mu \mathrm{m}$.

O mapa de distribuição dos valores da mediana (Fig. 8) diferencia a fácies de areia quartzosa do Canal de Itaparica da do Canal de Itaparica-Salvador. Desse modo (Tab. I), os materiais do Canal de Itaparica-Salvador apresentam, de uma maneira geral, valores da mediana $(>250 \mu \mathrm{m})$ mais altos do que os do Canal de Itaparica $(62-250 \mu \mathrm{m})$, embora, no último, possam ser encontrados valores superiores a $250 \mu \mathrm{m}$, como na parte estreita do canal, ao sul, e em parte de seu bordo do lado oeste. A fácies de areia quartzosa disposta nos bordos da baía e das pequenas ilhas apresenta, preferencialmente, valores entre $62-250 \mu \mathrm{m}$ podendo, localmente, apresentar valores entre 4-62 e superiores a $250 \mu \mathrm{m}$. As demais fácies apresentam, para os valores da mediana, padrões semelhantes aos dos demais mapas texturais, com as seguintes características: a) fácies de lama, valores da nediana inferiores a $4 \mu \mathrm{m}$; b) fácies de biodetritos, valores superiores a $250 \mu \mathrm{m}$ e c) fácies mista, valores entre 4 e $62 \mu \mathrm{m}$. A fácies mista na parte central da baía é separada da fácies de areia quartzosa no Canal de Itaparica-Salvador por uma faixa intermediária com valores da mediana entre 62 e $250 \mu \mathrm{m}$.

ORIGEM DOS SEDIMENTOS RECENTES Segundo Pontes (1969), por todo o bordo da Baía de Todos os Santos, afloram sedimentos do Supergrupo Bahia, com exceção de uma pequena parte, na costa do lado leste da baía, entre a entrada do canal e a pequena Baía de I tapagipe. Nessa área, aflora o embasamento cristalino, correspondendo a um trecho da Falha de Salvador, limite leste da Bacia do Recôncavo. O Supergrupo Bahia é caracterizado nas costas dos limites norte e leste da baia, bem como nas numerosas ilhas, pelas fácies do Cretáceo Inferior, representadas por folhelhos e siltitos cinza-esverdeados e por arenitos finos. $\mathrm{Na}$ costa do lado oeste, aparecem as fácies do Jurássico Superior, seqüência de camadas vermelhas constituída predominantemente de arenitos com intercalação de folhelhos. Essa sequiência se estende para oeste até uns $20 \mathrm{~km}$, em média, sendo limitada pela Falha de Maragogipe, limite oeste da Bacia do Recôncavo, em contato direto com o embasamento cristalino (Pontes, 1969). O Quaternário, na forma de terraços litorâneos esparsos, aflora nas costas dos limites norte e oeste da baía e na costa sudeste da llha de Itaparica.

Os sedimentos atualmente introduzidos na Baía de Todos os Santos, finos em suspensão, devem provir, em sua maior parte, da desagregação do embasamento cristalino, trazidos pelo Rio Paraguaçu. Esse rio lança na báa, notadamente em épocas da cheia, materiais que se depositam preferencialmente em sua metade norte, correspondendo à atual fácies de lama (Fig. 2). Em menor escala, deve-se considerar a contribuição dada pelos pequenos riachos e gamboas, pelo escoamento superficial e pela erosão marginal, que carreiam para a baía, notadamente nas partes norte e leste, os produtos da desagregação dos folhelhos e siltitos aí aflorantes. Não se pode desconhecer, ainda, a existência da Corrente do Brasil, que penetra a baía com competência suficiente para transportar materiais finos em suspensão, lançados ao mar pelos rios e riachos da costa oceânica ao norte de Salvador. Essa possibilidade pode ser sustentada pelos estudos de Pak et al. (1969), Costin (1970) e Drake (1971), demonstrando que os sedimentos finos podem viajar em 
suspensão na coluna d'água a partir da fonte de suprimento, através da plataforma, por longos percursos. Leão (1971) aponta a efetividade dessa corrente pela presença, nos sedimentos de fundo da parte norte da baía (Laje de Ipeba, Fig. 1), de carapaças de radiolários que teriam sido trazidos do mar aberto.

CONCLUSÓES Embora sejam praticamente inexistentes dados sobre os processos físicos atuantes na Baía de Todos os Santos, podem-se definir, para a baía, levando-se em conta os teores de argila nos sedimentos de fundo, áreas com níveis de energia distintos. O Canal de Itaparica-Salvador, com baixos teores de argila, corresponde à área de maior energia, sujeita à ação do fluxo e refluxo das marés. A àrea do Canal de Itaparica apresenta também baixos teores de argila, que podem estar relacionados ou a uma energia mecânica alta, como na entrada sul do canal, próximo a Caixa-Pregos ou, ainda, a um escasso suprimento de finos, em suspenșão. A área norte, ocupada pela fácies de lama, corresponde a uma região de fraca energia, onde provavelmente existe um grande suprimento de materiais finos em suspensão, trazidos pelo Rio Paraguaçu e por outros pequenos rios e riachos presentes. Nas áreas marginais, os teores de argila, quando baixos (inferiores a $10 \%$, devem estar relacionados à ação do winnowing (joeiramento), ligada particularmente à maré, que elimina os finos.

Magliocca e Kutner $(1964,1965)$ apontam a estreita relação entre o teor de matéria orgânica, a energia das águas e a granulometria dos sedimentos de fundo, em ambientes marinhos de água rasa recentes, na costa do Estado de São Paulo, "... mostrando, seu mapeamento, a localização das amostras de baixo conteúdo orgânico em zonas de maior movimentação das águas" e de maior granulometria. Essa associação é explicada pelos mesmos autores pelo fato de a matéria orgânica ser"... depositada sob as mesmas condições energéticas favoráveis à deposição de argilas, sendo, portanto, sua concentração maior nos sedimentos mais finos". Na Baía de Todos os Santos essa relação é bem observada ao se comparar as Figs. 2 e 4 , onde os maiores teores de matéria orgânica (Tab. 1) coincidem com as zonas calmas da fácies de lama e os menores com fácies de areia quartzosa no Canal de Itaparica-Salvador e na entrada sul do Canal de Itaparica, sujeitos a forte movimentação das águas.

- Os materiais encontrados no fundo da Baía de Todos os Santos, com base nas considerações feitas por Swift et al. (1971) para sedimentos ditos "relíquias" encontrados sobre plataformas continentais, são de três tipos, bem distintos: 1, material fino, argilo-siltoso, atual; 2, material-relíquia e 3, material palimpsest.

Material atual Corresponde à fácies de lama, que se estende por toda a área norte da baía, e ao material fino argilo-siltoso subordinado, nas fácies de biodetritos e mista (Figs. 2 e 6).

Material-relíquia Os sedimentos-relíquia, no sentido definido por Emery (1968), aparecem em duas áreas bem-marcadas da Baía de Todos os Santos: fácies de areia quartzosa nos canais de Itaparica e de Itaparica-Salvador (Fig. 2). Essas áreas, entretanto, podem ser diferenciadas quanto a seus materiais, levando-se em conta as características texturais de seus sedimentos. Desse modo, a fácies de areia quartzosa no canal de Itaparica-Salvador, considerando-se unicamente o quartzo, é comparável em selecionamento e arredondamento com modernas areias de praia ou de antepraia. Os materiais do Canal de Itaparica, por outro lado, por apresentarem menores arredondamentos e maiores percentagens de finos, com os grãos tendo, algumas vezes, um filme envoltório de argila, devem estar relacionados com antigas fases de acumulação deltaica do Rio Paraguaçu, apresentando-se a areia, em algumas partes, já fixada pela vegetação. 
Material "palimpsest" Swift et al. (1971) propuseram o termo palimpsest para sedimentos que apresentam uma mistura de atributos texturais e petrográficos de condições ambientais remanescentes do passado, atuantes no Quaternário, e de condições subseqüentes, mais recentes. $O$ termo palimpsest, portanto, implica a presença nos materiais-relíquia, de constituintes alóctones, tais como os sedimentos detríticos argilo-siltosos trazidos atualmente pelo Rio Paraguaçu. As fácies mista e de biodetritos (Fig. 2) no fundo da Baía de Todos os Santos, representadas por uma mistura de sedimentos-relíquia (conchas na fácies de biodetritos e areias quartzosas e conchas, na fácies mista) e material argilo-siltoso, recente, devem ser consideradas, desse modo, como do tipo palimpsest.

As características geomorfologicas da Baía de Todos os Santos, com muitas ilhas e bordos recortados, sugerem uma história geológica relativamente jovem, em conexão com uma rápida invasão do mar.

As profundidades das águas na Baía de Todos os Santos não excedem os $100 \mathrm{~m}$. Dessa maneira, toda essa área foi exposta durante a última idade glacial, época em que o nível do mar, segundo Guilcher (1969) estava a cerca de $120 \mathrm{~m}$ abaixo do nível atual. Tentaremos, em seguida, discutir a subseqüente transgressão ocorrida durante o fim do Pleistocenominício do Holoceno, levando em conta os dados atualmente disponíveis.

Dados de numerosas sondagens efetuadas na parte norte da baía pela Companhia de Cimento Salvador (GOCISA) indicam que os depósitos conchíferos, bem como o material atual argilo-siltoso, repousam diretamente sobre rochas cretáceas, atestando a ausência de sedimentos intermediários.

Provavelmente, durante a última grande fase regressiva do Quaternário, com um máximo atingido há cerca de 15000 anos A. P. (Milliman e Emery, 1968), a Baía de Todos os Santos passou a receber sedimentos clasticos de origem fluvial, principalmente do Rio Paraguaçu. Como observado por Kowsman e Costa (1974), ao estudarem paleolinhas de costa na plataforma continental brasileira, com o subsequiente episódio transgressivo durante o Flandriano (Bittencourt et al., 1974), os clásticos lançados na plataforma "... foram retrabalhados e selecionados, resultando numa maior concentração de terrígenos grosseiros no nível de maior energia, ou seja, na zona litorânea da época", a exemplo da fácies de areia quartzosa atualmente encontrada no Canal de Itaparica-Salvador. Como observam Bittencourt et al. (1974), próximo ao fim dessa fase, teve início a formação dos depósitos conchíferos. $O$ mar alcançou um nível acima do atual, não superior a $5 \mathrm{~m}$, como atestado pelos extensos terraços litorâneos ao longo da costa oeste da baía, que chegam até essa cota. A sedimentação argilo-siltosa, iniciada após o afogamento do Rio Paraguaçu e o desenvolvimento dos depositos conchíferos, permanece até os dias atuais.

Agradecimentos Os dois primeiros autores, pesquisadores do Programa de Pesquisa é Pos-Graduação em Geofisica da UFBa., querem deixar aqui assinaladas suas homenagens à memória do Prof. Enrico Di Napoli, comautor, que veio a falecer pouco antes da conclusão do trabalho. $O$ referido professor foi um inc̈ansável incentivador e formador de pesquisadores, dentro do Projeto "Geofisica e Geologia da Baia de Todos os Santos e da Plataforma Continental do Estado da Bahia", desde seu início, em 1970. À Srta. Moema Maltez Oliveira são expressos agradecimentos pela confecção dos mapas. Por fim, agradecimentos são extensivos às entidades financiadoras, MINIPLAN, BNDE e GNPq. 


\section{BIBLIOGRAFIA}

ANDREA, R. - 1962 - Chuvas na Bahia, DNOCS-CPE, Salvador, BA

BITTENCOURT, A. C. S. P. - 1975 - Sedimentação recente na Costa Atlântica de Salvador. Rev. Bras. Geoc. 5(1): 46-63

BITTENCOURT, A. G.S. P., BRICHTA, A. e DI NAPOLI, E. - 1974 - A Sedimentação na Baia de Aratu, Bahia. Rev. Bras. Geoc. 4(1): 51.63

BRICHTA, A. - 1973 - Sedimentos Recentes da Foz do Rio Paraguaçu. XXVII Congr. Bras. Geol., Resumo das Comunicaç⿸丆es, p. 202, Aracaju, SE

COSTIN, J. M. - 1970 - Visual observations of suspended-particle distribution at three sites in the Caribbean Sea. Journ. Geophys. Research, 75(21): 4 144-4150

Diretoria de Hidrografia e Navegação - 1963 - Carta de Correntes de Maré - Porto de Madre de Deus

Diretoria de Hidrografia e Navegação - 1970 - Roteiro da Marinha, 597 pp.

Diretoria de Hidrografia e Navegação - 1974 - Atlas de Cartas-Piloto - Oceano Atlântico, de Trinidad ao Rio da Prata

DRAKE, D. E. - 1971 - Suspended sediment and thermal stratification in Santa Barbara Channel, California. Deep-Sea Research 18: 763-769

EMERY, K. O. - 1968 - Relict sediments on Continental shelves of the world. Am. Assoc. Petroleum Geologists Bull, 52: 445-464

ESTEVAM, B. C. - 1971 - Estudo sedimentológico da Praia de Estela Maris, Salvador, Bahia. An. XXV Gongr. Bras. Geol. 2: 195-206

GUILCHER, A. - 1969 - Pleistocene and Holocene sea level changes. Earth Sci. Rev. 5: 69:97

KOWSMAN, R. O. e COSTA, M. P. A. - 1974 - Paleolinhas de costa na plataforma continental das regióes sul e norte brasileira. Rev. Bras. Geoc. 4(4): 215-222

KUTNER, A.S. - 1962 - Granulometria dos sedimentos de fundo da região de Cananéia, SP. Bol. Soc. Bras. Geol. 11(2): 41-54

LEAO, Z. M. A. N. - 1971 - O depósito conchífero da Lage de Ipeba, BA. Tese de Mestrado em Geociencias. Univ. Fed. Bahia (inédito)

MABESOONE, J. M. - 1971 - Fácies sedimentares da plataforma continental brasileira. Est. Sedimentol. 1(1): 55-71

MABESOONE, J. M. e GOUTINHO, P. N. - 1970 - Littoral and shallow Marine Geology of Northern and Northeastern Brazil, Trab. Oceanogr., Univ. Fed. Pernambuco 12: 1-214

MACHADO, A. J. - 1971 - Sedimentos recentes da Baia de Todos os Santos - Estudo sedimentológico da Praia de Inema, Bahia, XXV Congr. Bras. Geol., Resumo das Comunicaç̃̃es, pp. 18-19, Săo Paulo, SP

MAGLIOGGA, A. e KUTNER, A.S. - 1964 - Conteúdo orgânico dos sedimentos de fundo de Cananéia, São Paulo. Contribuiçð̌es Inst. Oceanogr. S. Paulo, Oceanogr. Fis. 7

MAGLIOGCA, A. e KUTNER, A.S. - 1965 - Sedimentos de fundo da enseada do Flamengo - Ubatuba. Contribuiçőes Inst. Oceanogr. S. Paulo, Oceanogr. Fís. 8

MILLIMAN, J. D. e EMERY, K. O. - 1968 - Sea levels during the past 35,000 years. Science 162: $1121-1123$

PAK, H., BEARDSLEY, G. B. Jr. e SMITH, R. L. - 1970 - An optical and hydrographic study of a temperature inversion off Oregon during upwelling. Journ. Geophys. Research 75(3): 629-638

PASSEGA, R., RIZZINI, A. e BORGHETTI, G. - 1967 - Transport of Sediments by waves, Adriatic Coastal shelf, Italy. Am Assoc. Petroleum Geologists Bull. 51: 1 304-1 319

PENTEAdO, A. R. - 1964 - O Atlântico Sul. In: Azevedo, A. (ed.), Brasil, a terra e $\alpha$ homem; vol, I - As bases fisicas, pp. 307.339. Comp. Edit. Nac., São Paulo

PONTES, A. R. - 1969 - Excursão às bacias Sedimentares do Recôncavo e Tucano Sul. XXIII Congr. Bras. Geol., Roteiro das Excursões, pp. 32-41. Salvador, BA

SHEPARD, F. P. - 1954 - Nomenclature based on sand-silt-clay ratio. Journ. Sed. Pet. 24: $151-158$ 
SHEPARD, F. P. e MOORE, D. G. - 1954 - Sedimentary environments differentiated by coarse fraction studies. Am. Assoc. Petroleum Geologists Bull. 38: $1792-1802$

SWIFT, D. J. P., STANLEY, D. J. e GURRAY, J. R. - 1971 - Relict sediments on continental shelves: a reconsideration. Journ. Geol. 79: 332-346

VILAS BÓAS, G. S. - 1971 - Sedimentos recentes da Baia de Todos os Santos - Alguns aspectos sedimentológicos recentes na costa leste da Baía de Todos os Santos, Bahia. XXV Congr. Bras. Geol., Resumo das Comunicaçð̃es, pp. 27-28. São Paulo, SP 